\title{
Efeito residual do extrato acetato de etila de Trichilia pallida Swartz (Meliaceae) para lagartas de diferentes idades de Spodoptera frugiperda (J. E. Smith, 1797) (Lepidoptera: Noctuidae)
}

\author{
Residual effect of ethyl acetate extract of Trichilia pallida Swartz (Meliaceae) for Spodoptera frugiperda \\ (J. E. Smith, 1797) (Lepidoptera: Noctuidae) larvae of diferents ages
}

Antonia Railda Roel $^{1}$ José Djair Vendramim ${ }^{2}$

RESUMO

Inseticidas de origem vegetal mostram limitada persistência em condições ambientais já que são degradados pela temperatura, por raios ultravioletas e por outros fatores ambientais. Com o objetivo de avaliar o efeito residual do extrato acetato de etila de Trichilia pallida, plantas de milho cultivadas em casa de vegetação foram pulverizadas com o referido extrato na concentração de $2 \%$, e as suas folhas utilizadas para alimentação de lagartas de Spodoptera frugiperda, em laboratório. As folhas foram oferecidas às lagartas aos 1, 3 e 7 dias após a pulverização, correspondendo cada época a um tratamento. Foram utilizados dois grupos de lagartas: recém-eclodidas e com 10 dias de idade. As folhas foram trocadas diariamente e, 10 dias após o início do experimento, foram avaliados a mortalidade, a largura da cápsula cefálica e o peso das lagartas. Verificou-se que, nas três épocas, o extrato reduziu a sobrevivência e prolongou o desenvolvimento larval. A intensidade destes efeitos foi maior quanto menor o intervalo entre a aplicação do extrato e o início do fornecimento das folhas aos insetos. Lagartas alimentadas com folhas tratadas com o extrato desde a eclosão foram mais afetadas que aquelas alimentadas a partir dos 10 dias.

Palavras-chave: plantas inseticidas, lagarta-do-cartucho-domilho, extrato de plantas.

\section{ABSTRACT}

Botanical pesticides have limited persistence in field conditions because are degraded by temperature, ultraviolet light and other environmental factors. Corn plants cultivated in greenhouse were sprayed with ethyl acetate extract of Trichilia pallida at the concentration of $2 \%$, and their leaves were offered to Spodoptera frugiperda larvae in order to evaluate the residual effect of the extract. The larval feeding began at 1, 3 and 7 days after the treatment with the extract. Two groups of larvae were evaluated: neonate and 10-day old ones. The leaves were daily replaced and after 10 days the mortality, the head capsules and the weight of larvae were evaluated. Independently of the residue age, all treatments affected larval survivorship and delayed larval development, but these effects were more pronounced for larvae fed one day treated leaves. The extract was more effective against neonate larvae than to 10 days old day larvae.

Key words: insecticide plants, fall armyworm, plant extracts.

\section{INTRODUÇÃO}

A lagarta-do-cartucho-do-milho Spodoptera frugiperda (J. E. Smith, 1797) (Lepidoptera: Noctuidae) é considerada uma das mais importantes pragas da cultura do milho pelo prejuízo que acarreta e pela dificuldade de seu controle, efetuado normalmente com inseticidas sintéticos. O uso freqüente de produtos químicos acarreta diversos problemas como resíduos nos alimentos, desequilíbrio biológico, intoxicação de operadores, aparecimento de populações resistentes aos inseticidas e outros. A busca de métodos alternativos ao controle químico inclui a utilização de produtos naturais que são menos agressivos ao ambiente, destacando-se entre estes os extratos botânicos.

Atualmente, a Família Meliaceae vem se destacando, dentre as diversas famílias botânicas, como uma das mais importantes fontes de produtos inseticidas devido ao número de espécies com

\footnotetext{
${ }^{1}$ Programa de Mestrado em Desenvolvimento Local, Universidade Católica Dom Bosco (UCDB), 79117-900, Campo Grande, MS, Brasil. E-mail arroel@ucdb.br.

${ }^{2}$ Departamento de Entomologia, Fitopatologia e Zoologia Agrícola, Escola Superior de Agricultura “Luiz de Queiroz” (ESALQ), 13418900, Piracicaba, SP, Brasil. E-mail jdvendra@esalq.usp.br.
} 
bioatividade à eficiência dos seus extratos. Muitas meliáceas vêm sendo pesquisadas como fontes de extratos inseticidas como o nim Azadirachta indica A. Juss, o cinamomo Melia azedarach L. (VENDRAMIM, 1997) e ainda espécies do gênero Trichilia (MIKOLAJCZAK \& REED, 1987; MIKOLAJCZAK et al., 1989; RODRÍGUEZ\&LAGUNES, 1992; RODRÍGUEZ \& VENDRAMIM, 1996; THOMAZINI et al., 2000; SOUZA \& VENDRAMIM, 2001; BOGORNI \& VENDRAMIM, 2003).

Trabalhos realizados na Escola Superior de Agricultura "Luiz de Queiroz"/USP evidenciaram a atividade inseticida de extratos aquosos de Trichilia pallida Swartz em relação à lagarta-do-cartucho $S$. frugiperda (RODRÍGUEZ \& VENDRAMIM, 1996; ROEL \& VENDRAMIM, 1999; ROEL et al., 2000 a e b; TORRECILLAS \& VENDRAMIM, 2001; BOGORNI \& VENDRAMIM, 2003). ROEL et al. (2000a) compararam diversos extratos não aquosos dessa planta e constataram que a fração acetato de etila obtida pela partição do extrato acetônico bruto de folhas e ramos foi a mais eficiente.

A utilização de produtos vegetais oferece vantagens em relação aos impactos ambientais e à segurança alimentar, pois não deixam resíduos nos alimentos e são facilmente degradados. Entretanto, dada a menor persistência, estes produtos se tornam pouco eficientes como pesticida, devido à necessidade de repetidas aplicações. De acordo com SCHMUTTERER (1990), os produtos naturais possuem limitada persistência no ambiente, sendo que temperatura, umidade, raios ultravioletas, $\mathrm{pH}$, chuva, entre outros, influenciam negativamente na sua atividade.

Assim, objetivou-se, nesse trabalho, avaliar o efeito residual da atividade inseticida do extrato acetato de etila de $\mathbf{T}$. pallida pulverizado em plantas de milho em casa de vegetação, em relação a lagartas de $\boldsymbol{S}$. frugiperda.

\section{MATERIAL E MÉTODOS}

Ramos (com folhas) de T. pallida, coletados no Parque Ecológico "Mata de Santa Genebra”, em Campinas, SP, foram secados em estufa de circulação (a $45^{\circ} \mathrm{C}$, por $48 \mathrm{~h}$ ) e moídos até a obtenção de um pó fino. Para obtenção do extrato, o pó foi misturado à acetona e a cada 24 h era feita decantação e filtração em papel de filtro, sendo a acetona novamente acrescentada ao material vegetal, até completar a extração. O extrato filtrado foi concentrado em rotaevaporador a $40^{\circ} \mathrm{C}$, a pressão reduzida, com uso de trompa de água. Os resíduos concentrados obtidos nas sucessivas extrações foram agrupados, resultando no extrato acetônico, que foi submetido a uma cromatografia de partição com acetato de etila, obtendo-se, então, o extrato utilizado.

Plantas de milho do genótipo Piranão com 10 dias de idade, cultivadas em sacos plásticos de 50 litros, em casa de vegetação, foram pulverizadas com o extrato diluído em acetona, na concentração de $2 \%$. A concentração foi estabelecida em função da atividade tóxica do extrato sobre $\boldsymbol{S}$. frugiperda, em ensaios anteriores (ROEL et al., 2000 a), sendo que se procurou atingir níveis tóxicos, em condições de exposição aos fatores ambientais. A pulverização das plantas foi realizada em diferentes intervalos para obter tempo residual inicial de 1, 3 e 7 dias. Como testemunha, foram utilizadas plantas pulverizadas com acetona. Foram utilizadas 30 plantas (distribuídas em espaçamento de $0,90 \times 0,20 \mathrm{~m}$ ) de cada tratamento, aplicando-se uma quantidade de suspensão (extrato a $2 \%$ ) equivalente a $200 \mathrm{~L} \mathrm{ha}^{-1}$.

Lagartas recém-eclodidas e com 10 dias de idade (criadas até então em dieta artificial, conforme BURTON \& PERKINS, 1972) foram mantidas em câmara climatizada (a $25 \pm 2{ }^{\circ} \mathrm{C}$, UR de $60 \pm 10 \%$ e fotofase de 14h) e alimentadas com folhas dessas plantas, pulverizadas ou não, as quais eram oferecidas diariamente. Foram utilizadas 40 lagartas de cada idade, recém-eclodidas e com 10 dias (quarto ínstar) para cada tratamento, em experimentos independentes. As folhas oferecidas às lagartas durante os 10 dias de duração do experimento eram de plantas submetidas a uma única pulverização, apresentando, assim, resíduos correspondentes aos intervalos de 1 a 10 dias, 3 a 13 dias e 7 a 17 dias, a contar da aplicação, respectivamente. O experimento foi avaliado com lagartas de duas idades, visando a simular as pulverizações com inseticidas em condições de campo, nas quais o produto é ingerido por lagartas de diferentes idades.

Dez dias após o início de cada experimento, as lagartas sobreviventes foram pesadas, mortas em álcool 70\% e avaliadas quanto à largura da cápsula cefálica. Essas medidas foram comparadas com os dados obtidos por FERRAZ (1982) para os seis ínstares larvais de $\boldsymbol{S}$. frugiperda para estabelecer a freqüência de lagartas por ínstar em cada tratamento.

Os dados de peso de lagartas e de largura da cápsula cefálica foram analisados por meio do programa estatístico SANEST (Versão 3.0) (ZONTA \& MACHADO, 1991). O delineamento experimental foi inteiramente casualizado, e a comparação entre as médias dos tratamentos foi feita pelo teste de Tukey a $5 \%$ de probabilidade de erro. 


\section{RESULTADOS E DISCUSSÃO}

Lagartas recém-eclodidas alimentadas com folhas tratadas: houve diferença na mortalidade larval acumulada de $\boldsymbol{S}$. frugiperda em função do período (dias), em que as folhas de milho foram tratadas antes de serem oferecidas às lagartas. Assim, enquanto no tratamento com folhas pulverizadas há um dia, a mortalidade foi de 83,3\%; nos tratamentos em que a pulverização tinha ocorrido há 3 e 7 dias, o valor foi de 23,3\%; contra 6,7\% de mortalidade na testemunha (pulverizada apenas com acetona) (Figura 1). Não foi observada fitotoxicidade nas plantas de milho pulverizadas com acetona (testemunhas) ou nos demais tratamentos.

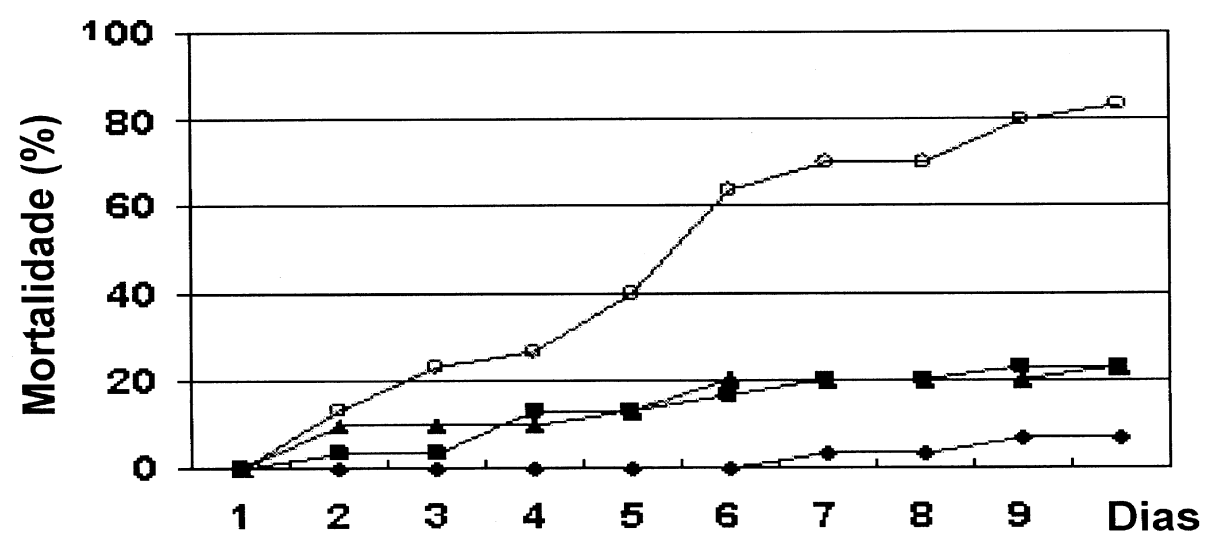

(A)

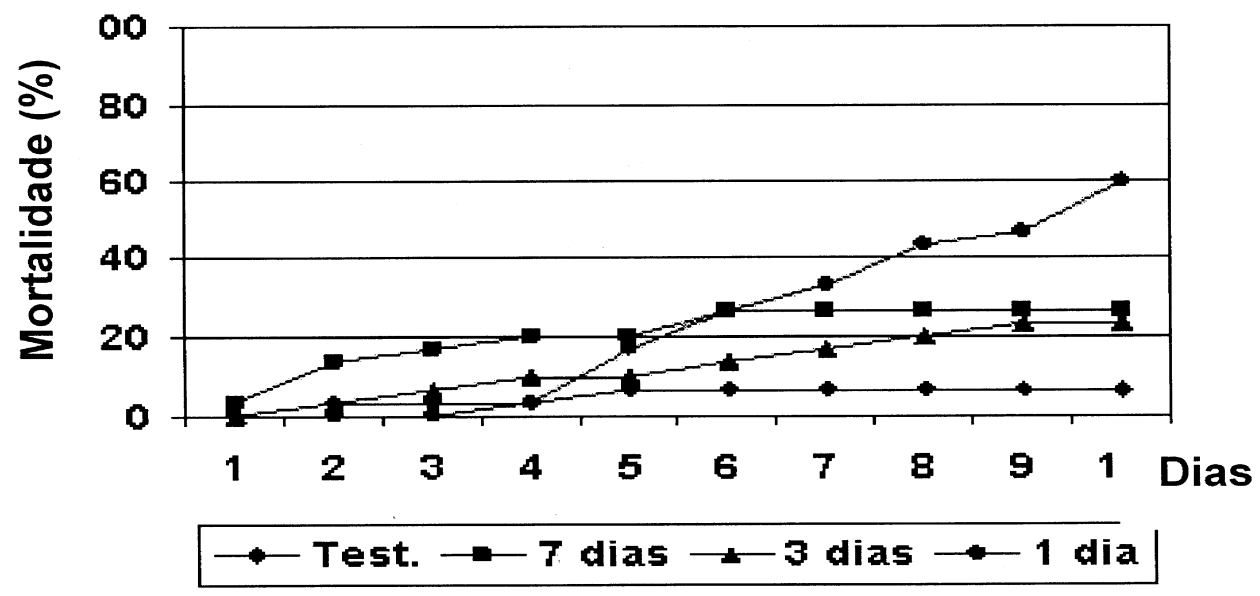

(B)

Figura 1 - Mortalidade diária acumulada de lagartas de $\boldsymbol{S}$. frugiperda, alimentadas desde a eclosão (A) e a partir dos 10 dias de idade (B), com folhas de milho pulverizadas com o extrato acetato de etila de $\mathbf{T}$. pallida, a $2 \%$, há 1 , 3 e 7 dias antes do início da alimentação. Temperatura: $25 \pm 2^{\circ} \mathrm{C}$; UR: $60 \pm 10 \%$; fotofase: $14 \mathrm{~h}$. 
Observou-se ainda que algumas lagartas morreram durante a ecdise sem conseguir liberar totalmente a exúvia, que ficava presa na parte posterior do corpo, o que já tinha sido relatado por ROEL \& VENDRAMIM (1999). Essas lagartas, quando examinadas ao microscópio, evidenciavam ecdise incompleta, como descrito por MARTINEZ (2002). Em relação à não-liberação da exúvia após a muda, MORDUE \& BLACKWELL (1993) mencionaram a ocorrência de sintomas semelhantes em lagartas submetidas a diferentes doses de azadiractina e atribuíram essas alterações à redução na concentração do ecdisônio ou atraso na sua liberação na hemolinfa. Efeito semelhante sobre espécies de lepidópteros foi observado com o uso de extratos de meliáceas, incluindo espécies de Trichilia (NAKATANI et al., 1981; KLOCKE, 1987; RODRÍGUEZ \& VENDRAMIM, 1996).

Não houve diferença nos pesos larvais em função da época de pulverização, mas em todos os tratamentos as lagartas pesaram menos que as criadas na testemunha. A redução do peso das lagartas sobreviventes em relação à testemunha variou de cerca de $80 \%$ (no tratamento com folhas pulverizadas há um dia) a aproximadamente $50 \%$ nos demais tratamentos (Tabela 1). A redução do peso dessa espécie de lagarta em decorrência do tratamento do substrato alimentar (folhas de milho) com extratos de T. pallida também foi relatada por TORRECILLAS \& VENDRAMIM (2001); RODRÍGUEZ \& VENDRAMIM (1996); ROEL \& VENDRAMIM (1999); BOGORNI \& VENDRAMIM (2003).

O atraso no desenvolvimento larval quando as lagartas receberam folhas tratadas foi confirmado pelas medições de cápsula cefálica (Tabela 2). Enquanto 37,8\% das lagartas já haviam atingido o 5o ínstar na testemunha, esse índice foi de 16,$1 ; 18,8$ e $0 \%$ nos tratamentos com pulverizações realizadas há 7, 3 e 1 dias, respectivamente. O inverso ocorreu com as lagartas no $3^{\circ}$ ínstar, para as quais a menor freqüência $(2,7 \%)$ foi registrada na testemunha e a maior $(37,5 \%)$ com pulverização há 1 dia. Todas as demais lagartas, no momento da avaliação, encontravam-se no $4^{0}$ ínstar.

Não houve diferença significativa no valor médio das cápsulas cefálicas entre os três tratamentos com extrato de plantas, embora em todos eles o valor tenha sido significativamente inferior ao registrado na testemunha (Tabela 1), indicando que, mesmo nas folhas tratadas há 7 dias por ocasião do início da alimentação das lagartas, ainda havia uma quantidade residual do extrato suficiente para prolongar o desenvolvimento larval da praga.

Lagartas alimentadas com folhas tratadas a partir dos 10 dias de idade: também para as lagartas com 10 dias de idade, foi constatada diferença na mortalidade larval acumulada de acordo com o período em que foi feito o tratamento antes do início da alimentação. Nesse caso, enquanto no tratamento com folhas tratadas há 1 dia, a mortalidade foi de 60,0\%, naqueles com pulverização há 3 e 7 dias, as mortalidades foram de 23,3 e 26,7\%, respectivamente, contra 6,7\% na testemunha (Figura 1). Apesar de as lagartas terem sido alimentadas até os 10 dias com dieta artificial, não se observou rejeição em decorrência da mudança do alimento.

O peso larval, entretanto, só foi reduzido nos tratamentos em que as pulverizações foram realizadas 1 e 3 dias antes das lagartas começarem a receber folhas tratadas. Nesses tratamentos, os pesos foram cerca de 77 e $38 \%$ menores que na testemunha, respectivamente, e diferiram também do valor registrado para as lagartas que receberam folhas tratadas 7 dias antes (Tabela 1).

O atraso no desenvolvimento larval evidenciado pela diferença no peso foi ratificado,

Tabela 1 - Peso ( \pm EP) e largura da cápsula cefálica ( \pm EP) de lagartas de $S$. frugiperda alimentadas, por 10 dias (a partir da eclosão e a partir dos 10 dias de idade), com folhas de milho pulverizadas com o extrato acetato de etila de T. pallida, a 2\%, há 7, 3 e 1 dias antes do início da alimentação. Temperatura: $25 \pm 2^{\circ} \mathrm{C}$; UR: $60 \pm 10 \%$; fotofase: $14 \mathrm{~h}$.

\begin{tabular}{llclc}
\hline \multirow{2}{*}{ Tratamento } & \multicolumn{2}{c}{ Lagartas alimentadas desde recém-eclodidas } & \multicolumn{2}{c}{ Lagartas alimentadas a partir dos 10 dias } \\
\cline { 2 - 5 } & \multicolumn{1}{c}{ Peso $(\mathrm{mg}) *$} & Cápsula cefálica (mm)* & Peso (mg)* & Cápsula cefálica (mm)* \\
\hline Testemunha & $52,8 \pm 31,5 \mathrm{a}$ & $1,46 \pm 0,13 \mathrm{a}$ & $322,1 \pm 102,8 \mathrm{a}$ & $2,52 \pm 0,11 \mathrm{a}$ \\
7 dias & $23,7 \pm 17,4 \mathrm{~b}$ & $1,08 \pm 0,09 \mathrm{~b}$ & $306,4 \pm 71,4 \mathrm{a}$ & $2,32 \pm 0,08 \mathrm{ab}$ \\
3 dias & $25,4 \pm 19,1 \mathrm{~b}$ & $1,14 \pm 0,09 \mathrm{~b}$ & $200,0 \pm 87,1 \mathrm{~b}$ & $1,79 \pm 0,09 \mathrm{c}$ \\
1 dia & $11,2 \pm 8,6 \mathrm{~b}$ & $1,02 \pm 0,07 \mathrm{~b}$ & $75,2 \pm 44,8 \mathrm{c}$ & 11,19 \\
CV(\%) & 1,24 & 24,51 & 3,58 & $\mathrm{~b}$ \\
\hline
\end{tabular}

*Médias seguidas da mesma letra na coluna, não diferem entre si pelo teste de Tukey $(\mathrm{P} \leq 0,05)$.

Ciência Rural, v.36, n.4, jul-ago, 2006. 
Tabela 2 - Freqüência (\%), por ínstar, de lagartas de $\boldsymbol{S}$. frugiperda alimentadas, por 10 dias (recém-eclodidas e a partir de 10 dias de idade), com folhas de milho pulverizadas com o extrato acetato de etila de $\mathbf{T}$. pallida, a 2\%, há 7, 3 e 1 dias antes do início da alimentação. Temperatura: $25+2{ }^{\circ} \mathrm{C}$; UR: $60+10 \%$; fotofase: $14 \mathrm{~h}$.

\begin{tabular}{|c|c|c|c|c|c|c|}
\hline \multirow{3}{*}{ Tratamento (dias) } & \multicolumn{6}{|c|}{ Freqüência por ínstar } \\
\hline & \multicolumn{3}{|c|}{ Lagartas alimentadas desde recém-eclodidas } & \multicolumn{3}{|c|}{ Lagartas alimentadas a partir dos 10 dias } \\
\hline & $3^{\circ}$ & $4^{\circ}$ & $5^{\circ}$ & $4^{\circ}$ & $5^{\circ}$ & $6^{\circ}$ \\
\hline Testemunha & 2,7 & 59,5 & 37,8 & 0 & 11,4 & 88,6 \\
\hline 7 dias & 19,4 & 64,5 & 16,1 & 0 & 31,2 & 68,8 \\
\hline 3 dias & 28,1 & 53,1 & 18,8 & 0 & 64,7 & 35,3 \\
\hline 1 dia & 37,5 & 62,5 & 0 & 9,1 & 86,4 & 4,5 \\
\hline
\end{tabular}

também nesse experimento, pelos dados de freqüência de lagartas por ínstar (Tabela 2). Assim, enquanto 88,6\% das lagartas já haviam atingido o 6o ínstar na testemunha, nos demais tratamentos esses percentuais foram de 68,8; 35,3 e 4,5\% com pulverização há 7, 3 e 1 dias, respectivamente, ocorrendo tendências opostas em relação ao percentual de lagartas no $5^{\circ}$ ínstar, nos respectivos tratamentos (11,4; 31,2; 64,7 e 86,4\%). O único tratamento em que ainda existiam lagartas no $4^{\circ}$ ínstar foi aquele com pulverização mais recente (1 dia).

A diferença na distribuição das lagartas por ínstar nos diversos tratamentos foi confirmada pelas medidas das cápsulas cefálicas das lagartas sobreviventes, observando-se, nos tratamentos com pulverização há 3 e 1 dias, valores médios de cápsula cefálica inferiores aos da testemunha. O valor obtido no tratamento com pulverização há 7 dias foi intermediário, não diferindo da testemunha e da pulverização há 3 dias (Tabela 1).

A ocorrência de mortalidade larval e desenvolvimento mais lento da praga constatada nesse trabalho estão de acordo com os dados obtidos por ROEL et al. (2000a); TORRECILLAS \& VENDRAMIM (2001), que verificaram o mesmo efeito com o emprego de extrato acetato de etila e aquoso, respectivamente, de ramos de $\mathbf{T}$. pallida.

A redução na sobrevivência larval e o prolongamento do período de desenvolvimento dos insetos foram mais pronunciados quando as lagartas passaram a receber folhas pulverizadas com extrato desde a eclosão, em comparação com aquelas em que isso ocorreu a partir dos 10 dias. Este maior efeito constatado sobre lagartas mais jovens de $\boldsymbol{S}$. frugiperda também foi observado por ROEL et al. (2000a), com concentração mais baixa $(0,006 \%)$ desse mesmo extrato aplicado diariamente nas folhas antes do fornecimento destas às lagartas, e por HELLPAP (1984), com extratos etanólicos e hexânicos de sementes de nim incorporados em dieta artificial. Situação inversa foi relatada por MARTINEZ \& VAN ENDEM (2001) com lagartas pequenas ( $3^{\circ}$ ínstar) e grandes (último ínstar) de Spodoptera littoralis alimentadas com dieta artificial acontendo 0,3 e 0,6 ppm de azadiractina.

Por outro lado, os efeitos do extrato foram mais pronunciados quanto menor o intervalo entre a pulverização foliar e o início da alimentação larval. Verificou-se, entretanto, que mesmo as folhas tratadas sete dias antes do início do experimento apresentavam resíduos do extrato. As diferenças entre os tratamentos ficaram evidentes quando as lagartas foram separadas por freqüência dos ínstares, observando-se maior suscetibilidade das lagartas mais jovens.

\section{CONCLUSÕES}

O extrato acetato de etila de ramos (com folhas) de Trichilia. pallida, impregnado em folhas de milho, possui efeito residual sobre lagartas de Spodoptera. frugiperda, mesmo com a utilização de substrato alimentar tratado sete dias antes do início do experimento. $\mathrm{O}$ extrato causa mortalidade e atrasa o desenvolvimento tanto em lagartas recém-eclodidas como naquelas alimentadas a partir dos 10 dias de idade, sendo os efeitos mais pronunciados nas lagartas mais jovens.

\section{AGRADECIMENTOS}

Os autores agradecem a Rosa Maria Shiraishi Frighetto (Embrapa Meio Ambiente) e a Nelson Frighetto (Centro de Pesquisa Pluridisciplinar de Química Biológica e Agronômica, CPQBA/UNICAMP), pelo auxílio no preparo dos extratos.

\section{REFERÊNCIAS}

BOGORNI, P.C.; VENDRAMIM, J.D. Bioatividade de extratos aquosos de Trichilia spp. sobre Spodoptera frugiperda (J.E. Smith) (Lepidoptera: Noctuidae) em milho. Neotropical Entomology, Londrina, v.32, p.665-669, 2003. 
BURTON, R.L.; PERKINS, W.D. WSB, a new laboratory diet for the corn earworm and the fall armyworm. Journal of Economic Entomology, Baltimore, v.65, p.385-386, 1972.

FERRAZ, M.C.V.D. Determinação das exigências térmicas de Spodoptera frugiperda (J.E. Smith, 1797) (Lepidoptera, Noctuidae) em cultura de milho. 1982. 81f. Dissertação (Mestrado em Entomologia) - Curso de Pós-graduação em Entomologia, Escola Superior de Agricultura Luiz de Queiroz, Piracicaba.

HELLPAP, C. Effects of neem kernel extracts on the fall armyworm Spodoptera frugiperda. In: Natural pesticides from the neem tree (Azadirachta indica A. Juss) and other tropical plants. Eschborn: GTZ, 1984. p.353-363.

KLOCKE, J.A. Natural plant compounds useful in insect control. In: WALLER, G.R. (Ed.) Allelochemicals: role in agriculture and forestry. Washington: American Chemical Society, 1987. p.396-415. (ACS Symposium Ser., 330).

MARTINEZ, S.M. (Ed). O nim - Azadirachta indica: natureza, usos múltiplos, produção. Londrina: Instituto Agronômico do Paraná, 2002. 142p.

MARTINEZ, S.M.; VAN ENDEM, H.F. Growth disruption, abnormalities and mortality of Spodoptera littoralis caused by azadirachtin. Neotropical Entomology, Londrina, v.30, p.113-125, 2001.

MIKOLAJCZAK, K.L.; REED, D.K. Extractives of seeds of the Meliaceae: Effects on Spodoptera frugiperda (J.E. Smith), Acalymma vittatum (F.), and Artemia salina Leach. Journal of Chemical Ecology, New York, v.13, p.99-111, 1987.

MIKOLAJCZAK, K.L. et al. Effect of meliaceous seed extracts on growth and survival of Spodoptera frugiperda (J.E. Smith). Journal of Chemical Ecology, New York, v.15, p.121-128, 1989

MORDUE A.J.; BLACKWELL, A. Azadirachtin: an update. Journal of Insect Physiology, Oxford, v.39, p.903-924, 1993.

NAKATANI, M. et al. Isolation and structures of trichilins, antifeedants against the Southern army worm. Journal of American Chemical Society, Champaign, v.103, p.12281230, 1981.

RODRÍGUEZ H.C.; LAGUNES T.A. Plantas con propiedades insecticidas: resultados de pruebas experimentales en laboratorio, campo y granos almacenados. Agroproductividad, Montecillo, v.1, p.17-25, 1992.

RODRÍGUEZ H.C.; VENDRAMIM, J.D. Avaliação da bioatividade de extratos aquosos de Meliaceae sobre Spodoptera frugiperda (J.E. Smith). Revista da Agricultura, Piracicaba, v.72, p.305-318, 1996.

ROEL, A.R.; VENDRAMIM, J.D. Desenvolvimento de Spodoptera frugiperda (J.E. Smith) em genótipos de milho tratados com extrato acetato de etila de Trichilia pallida (Swartz). Scientia Agricola, Piracicaba, v.56, p.581-586, 1999.

ROEL, A.R. et al. Atividade tóxica de extratos orgânicos de Trichilia pallida (Swartz) (Meliaceae) sobre Spodoptera frugiperda (J.E. Smith). Anais da Sociedade Entomológica do Brasil, Londrina, v.29, p.799-808, 2000a.

ROEL, A.R. et al. Efeito do extrato acetato de etila de Trichilia pallida (Swartz) (Meliaceae) no desenvolvimento e sobrevivência da lagarta-do-cartucho. Bragantia, Campinas, v.59, p.53-58, 2000b.

SCHMUTTERER, H. Properties and potential of natural pesticides from the neem tree, Azadirachta indica. Annual Review of Entomology, Palo Alto, v.35, p.271-297, 1990.

SOUZA, A.P.; VENDRAMIM, J.D. Atividade inseticida de extratos aquosos de meliáceas sobre a mosca-branca Bemisia tabaci (Gennadius) biótipo B (Hemiptera: Aleyrodidae). Neotropical Entomology, Londrina, v.30, p.133-137, 2001.

THOMAZINI, A.P.B.W. et al. Extratos aquosos de Trichilia pallida e a traça-do-tomateiro. Scientia Agricola, Piracicaba, v.57, p.13-17, 2000.

TORRECILLAS, S.M.; VENDRAMIM, J.D. Extratos aquosos de ramos de Trichilia pallida e o desenvolvimento de Spodoptera frugiperda em genótipos de milho. Scientia Agricola, Piracicaba, v.58, p.27-31, 2001

VENDRAMIM, J.D. Uso de plantas inseticidas no controle de pragas. In: CICLO DE PALESTRAS SOBRE AGRICULTURA ORGÂNICA, 2., 1997, São Paulo. Palestras... Campinas: Fundação Cargill, 1997. p.64-69.

ZONTA, E.P.; MACHADO, A.A. Sistema de análise estatística para microcomputadores (SANEST). Pelotas: UFPel - Departamento de Matemática e Estatística, 1991. $101 p$. 